\title{
Analisa Beban Kerja dan Gaya Dinamis pada Round Roller dan Sliding Roller untuk Sistem CVT (Continuously Variable Transmission) Sepeda Motor Matic
}

\author{
Ahmad Bagus Prasojo dan Yusuf Kaelani \\ Jurusan Teknik Mesin, Fakultas Teknologi Industri, Institut Teknologi Sepuluh Nopember (ITS) \\ Jl. Arief Rahman Hakim, Surabaya 60111 Indonesia \\ e-mail: y_kaelani@me.its.ac.id
}

\begin{abstract}
Abstrak-Primary shave weight atau sering disebut roller merupakan salah satu komponen dari sistem CVT pada motor matik yang sering mengalami kerusakan, baik itu aus maupun crack atau pecah. Metodologi yang dilakukan pada penelitian ini adalah menganalisa beban kerja (gaya) yang dialami oleh roller. Selanjutnya akan dihitung besar tegangan (stress) yang terjadi pada roller menggunakan teori tegangan kontak (contact stress). Kemudian analisa akan dilanjutkan menggunakan teori kelelahan (fatigue). Gaya normal yang didapat pada posisi stasioner sebesar $37,268 \mathrm{~N}$ dan posisi puncak sebesar 525,279 $\mathrm{N}$. Untuk total tegangan ekivalen yang terjadi berbeda dikarenakan luasan kontaknya, round roller dengan luasan kontak yang lebih kecil menghasilkan total tegangan yang lebih besar yaitu 21,423 $\mathrm{MPa}$ sedangkan sliding roller sebesar 14,559 MPa. Dengan frekuensi real pembebanan roller sebesar $0,0667 \mathrm{~Hz}$ dan berdasarkan teori kelelahan Gerber stress amplitude round roller didapatkan 8,8756 Mpa dan untuk sliding roller sebesar 6,195 Mpa. Jadi setelah stress amplitude dipetakan pada sn-curve PTFE hasil prediksi umur untuk round roller adalah $4,081 \approx 4$ bulan dan untuk sliding roller adalah $5,89 \approx 6$ bulan.
\end{abstract}

Kata kunci - gaya normal, round roller, sliding roller, tegangan kontak, teori kelelahan Gerber, umur pakai

\section{PENDAHULUAN}

$\mathrm{J}^{2}$ UMLAH pengguna motor matic di Indonesia, dalam 5 tahun terakir ini terus mengalami peningkatan. Berdasarkan statistik penjualan motor yang dicatatkan oleh Asosiasi Industri Sepeda Motor Indonesia (AISI) Pada tahun 2011 sebesar 4,15 juta unit $(51,81 \%)$, tahun 2012 sebesar 4,23 juta unit $(59,33 \%)$ pada tahun 2013 sebesar 4,89 juta unit $(63,02 \%)$, tahun 2014 mencapai 5,32 juta unit $(67,33 \%)$, pada tahun 2015 sebesar 4,87 juta unit $(75,27 \%)$ dan pada tahun 2016 dapat dipastikan akan mengalami peningkatan pengguna motor matik di Indonesia.

Primary shave weight atau sering disebut roller merupakan salah satu komponen dari sistem CVT pada motor automatic yang sering mengalami kerusakan, baik itu aus maupun crack atau pecah, seperti yang ditunjukkan pada gambar 1. Adapun beberapa penyebab kerusakan dari roller seperti kurangnya perawatan pada sistem CVT, membuka tutup handle gas secara spontan, atau terkena kontaminasi zat-zat yang dapat menggangu kinerja dari roller seperti debu, lumpur, dan lainlain.

Bentuk geometri roller pada umumnya yaitu silinder (round roller) dengan rongga di tengah dan terdiri dari dua lapisan, yaitu bagian dalam terbuat dari logam (tembaga, kuningan, aluminium, dll) sedangkan bagian luar terbuat dari bahan non logam (plastik, teflon, polycarbonate, nylon, dll). Namun, ada perusahaan pembuat part sepeda motor di Taiwan membuat sebuah roller dengan bentuk asimetris yang disebut sliding roller. Mereka menyebut sliding roller dapat bekerja lebih baik daripada roller standar (round roller) yang beredar di pasaran, dapat meningkatkan akselerasi dan umur pakai (lifetime) dari sliding roller lebih panjang.

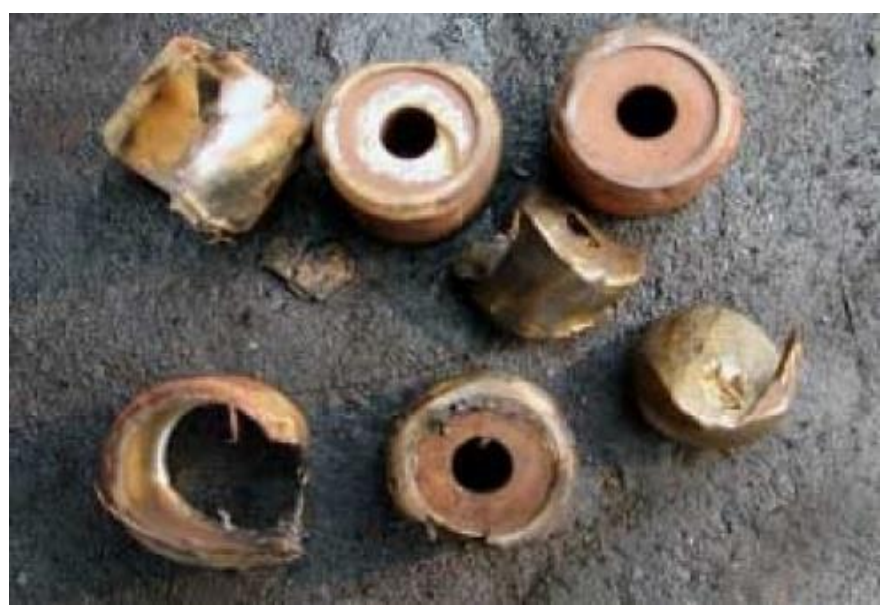

Gambar 1. Kerusakan pada roller

Pada penelitian sebelumnya belum ada yang spesifik membahas tentang gaya-gaya yang terjadi pada roller, khususnya sliding roller ini. Kebanyakan membahas tentang round roller dengan variasi berat maupun diameter round roller itu sendiri. Oleh karena itu di dalam penelitian ini penulis mencoba untuk menganalisa sebesar apa gaya-gaya yang terjadi pada roller CVT matic, baik itu round roller maupun sliding roller dan juga penulis akan mencoba membandingkan antara kedua jenis roller tersebut, apa kekurangan dan kelebihan dari keduanya. 


\section{URAIAN PENELITIAN}

\section{A. Transmisi Otomatis}

Transmisi otomatis adalah transmisi kendaraan yang pengoperasiannya dilakukan secara otomatis dengan memanfaatkan gaya sentrifugal. Transmisi yang digunakan yaitu transmisi otomatis "V" belt atau yang dikenal dengan CVT (Continuous Variable Transmission). CVT adalah sistem transmisi daya dari mesin menuju ban belakang menggunakan sabuk yang menghubungkan antara drive pulley dengan driven pulley menggunakan prinsip gaya gesek.

Pulley Penggerak/ pulley primer (Drive Pulley/ Primary Pulley) adalah komponen yang berfungsi mengatur kecepatan sepeda motor berdasar gaya sentrifugal dari roller, yang terdiri dari beberapa komponen seperti yang ditunjukkan pada gambar 2.

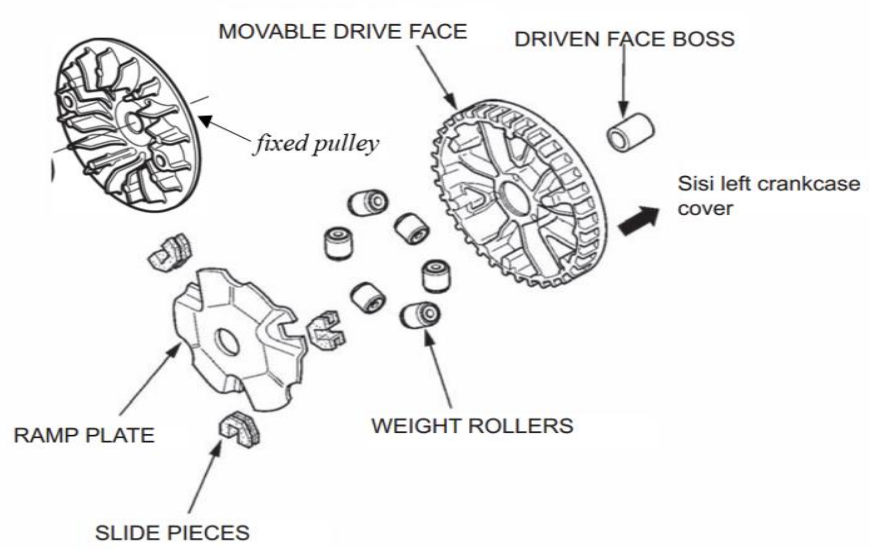

Gambar 2. Komponen pulley primer [6]

Fixed Pulley atau kipas pendingin merupakan komponen pulley penggerak tetap. Selain berungsi untuk memperbesar perbandingan rasio di bagian tepi komponen ini terdapat kipas pendingin yang berfungsi sebagai pendingin ruang CVT agar belt tidak cepat panas dan aus. Pulley Penggerak / movable drive face Pulley penggerak merupakan komponen pulley yang bergerak menekan CVT agar diperoleh kecepatan yang diinginkan.

\section{B. Analisa Gaya Pada Roller Penggerak}

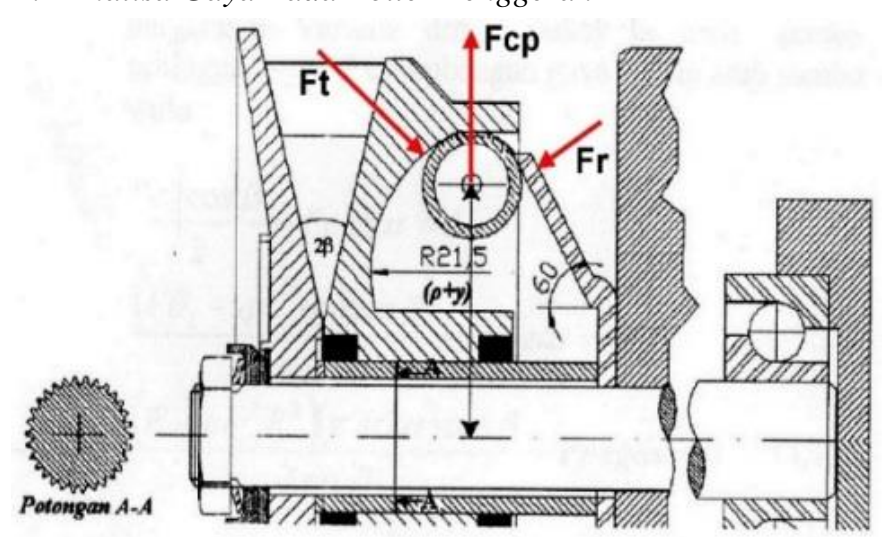

Gambar 3. Diagram benda bebas dari roller penggerak [5]

Untuk menghitung besarnya harga Ft pada tiap titik garis singgung kurva lingkaran kita dapat menggunakan rumusan sebagai berikut:

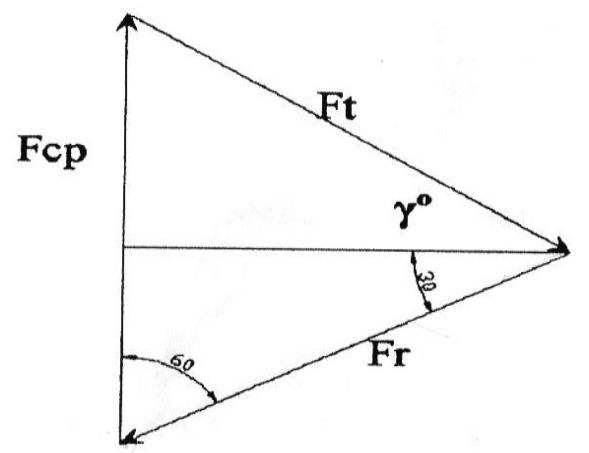

Gambar 4. Poligon segitiga gaya [5]

Berdasarkan gambar 4 didapatkan:

$\frac{F t}{\sin 60^{\circ}}=\frac{F c p}{\sin \left(30^{\circ}+\gamma^{\circ}\right)}=\frac{F c p \times \sin 60^{\circ}}{\sin \left(30^{\circ}+\gamma^{\circ}\right)}$

Dimana $F_{c p}$ adalah gaya sentrifugal

$$
F c p=m \omega^{2}(\rho+y)
$$

Dimana $: M=$ massa roller

$$
\begin{aligned}
& \omega=\text { kecepatan sudut }\left(\frac{\mathrm{rad}}{\operatorname{detik}}\right) \\
& \rho=\text { radius putar awal }
\end{aligned}
$$

\section{Tegangan Kontak (Contact Stress)}

Tegangan kontak adalah tegangan yang terjadi ketika salah satu atau kedua benda memiliki permukaan melengkung ditekan bersama-sama, titik atau garis kontak berubah menjadi kontak area.

Kontak Silinder (Cylindrical Contact) gambar 5(a) menggambarkan situasi yang sama dimana unsur-unsur menghubungi dua silinder panjang 1 dan diameter $d_{1}$ dan $d_{2}$. Seperti yang ditunjukkan pada gambar 5(b), daerah kontak adalah persegi panjang sempit $2 \mathrm{~b}$ lebar dan panjang 1 , dan distribusi tekanan berbentuk bulat panjang. Lebar setengah $b$ diberikan oleh:

$b=\sqrt{\frac{2 F}{\pi l} \frac{\left(1-v_{1}^{2}\right) / E_{1}+\left(1-v_{2}^{2}\right) / E_{2}}{1 / d_{1}+1 / d_{2}}}$

Tekanan Maksimal adalah

$p_{\max }=\frac{2 F}{\pi b l}$ 


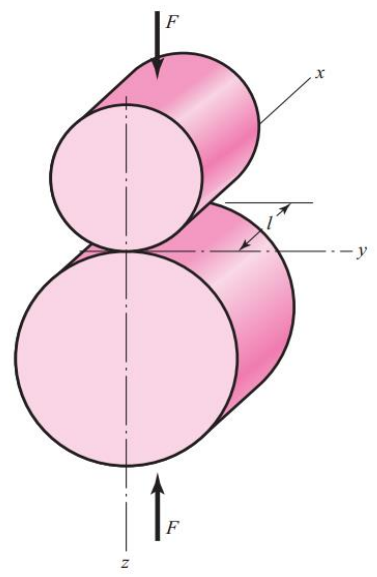

(a)

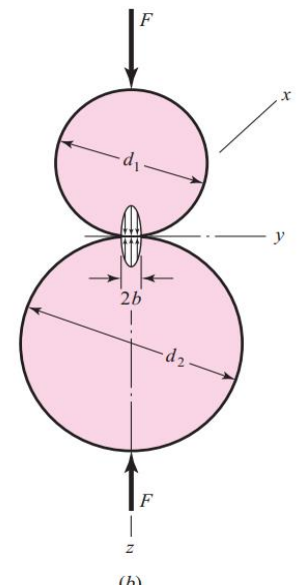

(b)
Gambar 5. Dua silinder sirkular yang tepat diadakan di kontak oleh Gaya $F$ merata sepanjang silinder panjang 1 (a) Tegangan Kontak memiliki elips distribusi di seluruh zona kontak lebar $2 b$ (b) [3]

$\sigma_{x}=-2 v p_{\max }\left[\sqrt{\left(1+\frac{z^{2}}{b^{2}}\right)}-\left|\frac{z}{b}\right|\right]$

$\sigma_{y}=-p_{\max }\left[\frac{1+2 \frac{z^{2}}{b^{2}}}{\left(\sqrt{1+\frac{z^{2}}{b^{2}}}\right)}-2\left|\frac{z}{b}\right|\right]$

$\sigma_{3}=\sigma_{z}=\frac{-p_{\max }}{\sqrt{\left(1+\frac{z^{2}}{b^{2}}\right)}}$

Ketiga persamaan diplot pada gambar 6 hingga jarak $3 \mathrm{~b}$ bawah permukaan. Untuk $0 \leq z \leq 0.436 \mathrm{~b}, \sigma_{l}=\sigma_{x}$, dan $\tau_{\max }=\left(\sigma_{l}\right.$ $\left.-\sigma_{3}\right) / 2=\left(\sigma_{x}-\sigma_{z}\right) / 2$. Untuk $z \geq 0.436 \mathrm{~b}, \sigma_{l}=\sigma_{y}$, dan $\tau_{\max }=\left(\sigma_{y}-\right.$ $\left.\sigma_{z}\right) / 2$. Sebuah plot $\tau_{\max }$ juga termasuk dalam gambar 6 , di mana nilai terbesar terjadi pada $z / b=0,786$ dengan nilai 0.300 pmax. Hertz (1881) memberikan model matematika sebelumnya dari bidang tegangan ketika zona kontak bebas dari tegangan geser.

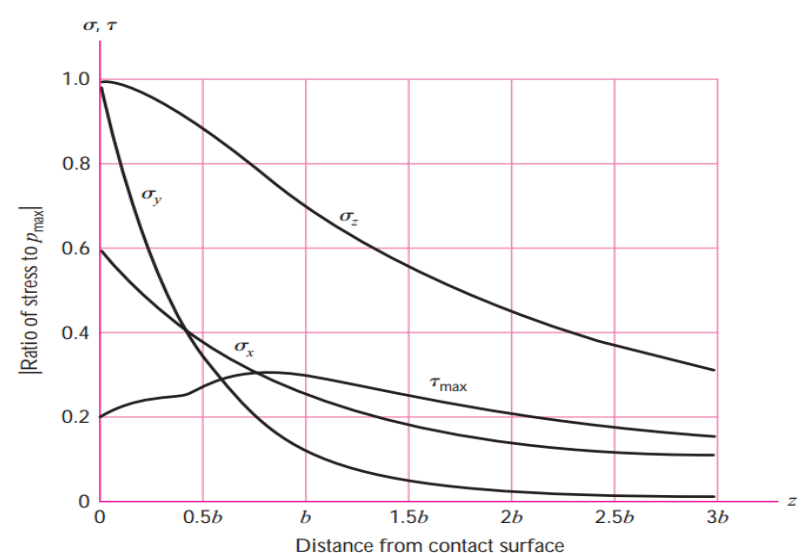

Gambar 6. Besaran komponen tegangan di bawah permukaan sebagai fungsi maksimal tekanan untuk kontak silinder [3]

\section{Teori Kelelahan (Fatigue)}

Metode Gerber - Hubungan antara tegangan variabel $\left(\sigma_{v}\right)$ dan tegangan rata-rata $\left(\sigma_{m}\right)$ untuk beban aksial dan beban tekuk (bending) untuk material lentur ada pada gambar 7 Sebuah kurva parabolik digambar antara batas ketahanan (endurance limit) dan tegangan tarik maksimum (ultimate tensile strength) disarankan oleh Gerber pada taun 1874.

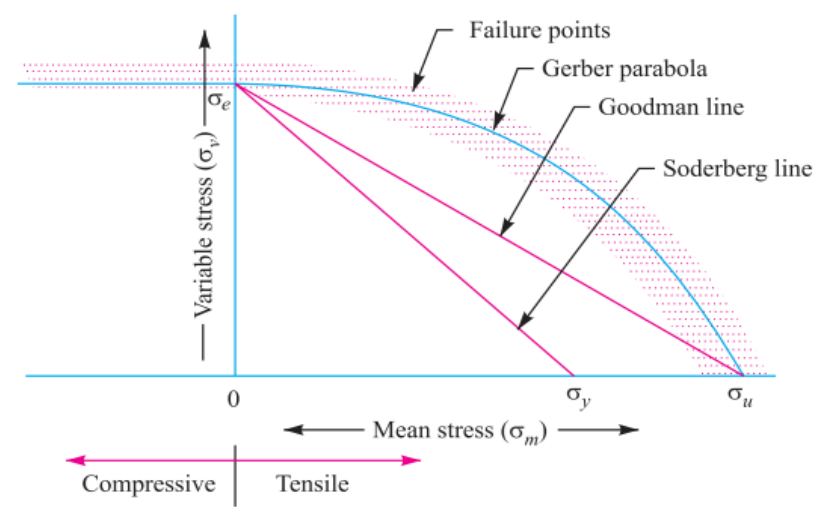

Gambar 7. Gabungan tegangan rata-rata dan variabel [2]

Berdasarkan Gerber, tegangan variabel (variable stress),

$\sigma_{v}=\sigma_{e}\left[\frac{1}{F . S .}-\left(\frac{\sigma_{m}}{\sigma_{u}}\right)^{2} F . S.\right]$

atau

$\frac{1}{F . S .}=\left(\frac{\sigma_{m}}{\sigma_{u}}\right)^{2} F . S .+\frac{\sigma_{v}}{\sigma_{e}}$

dimana,

$F . S .=$ faktor keamanan

$\sigma_{m}=$ tegangan rata-rata (tarik atau tekan),

$\sigma_{u}=$ tegangan maksimum (tarik atau tekan)

$\sigma_{e}=$ batas ketahanan untuk beban berlawanan (reversal)

Karena nilai dari faktor konsentrasi tegangan kelelahan $\left(K_{f}\right)$, maka persamaan diatas menjadi

$\frac{1}{F . S .}=\left(\frac{\sigma_{m}}{\sigma_{u}}\right)^{2} F . S .+\frac{\sigma_{v} \times K_{f}}{\sigma_{e}}$

\section{METODE PENELITIAN}

Penyusunan tugas akhir ini diawali dengan studi literatur mengenai continuously variable transmission (CVT) pada sepeda motor matik, khususnya pada bagian Primary shave weight atau sering disebut Roller, merumuskan masalah masalah yang akan dibahas, mengumpulkan data-data mengenai round roller dan sliding roller beserta dimensinya, menentukan variasi kecepatan driver pulley yang akan dianalisa, menentukan variasi bentuk geometri dari roller.

Data dari roller yang akan dijadikan sebagai objek penelitian ini bersumber dari hasil pengukuran, bentuk geometris dari roller standar seperti yang ditunjukkan pada gambar 8 . Konstruksi dari roller sendiri tersusun dari dua material yang berbeda, material terluar adalah material non logam yaitu teflon, kemudian material yang didalam yaitu material logam yaitu tembaga. 


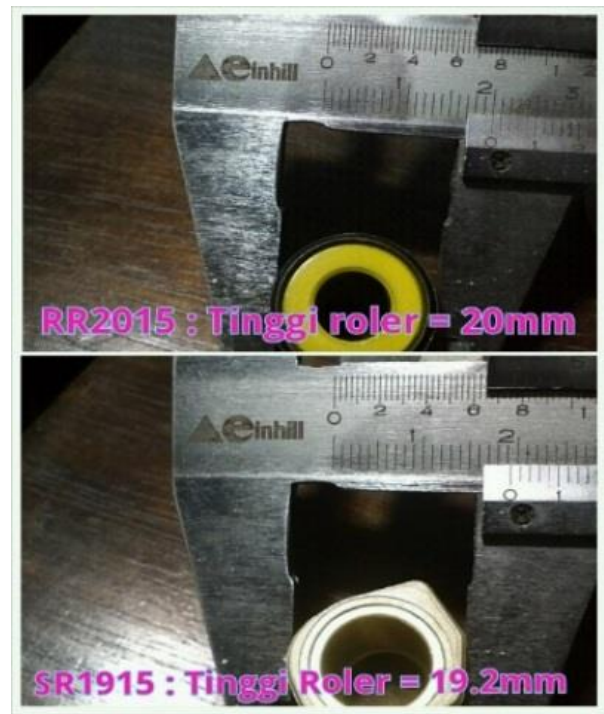

Gambar 8. Diameter round roller dan sliding roller

Tabel 1.

Spesifikasi material roller teflon / PTFE dan tembaga

\begin{tabular}{|c|c|}
\hline \multicolumn{2}{|c|}{ PTFE } \\
\hline Property & Value \\
\hline Density & $2200 \mathrm{~kg} / \mathrm{m}^{3}$ \\
\hline Melting Point & $600 \mathrm{~K}$ \\
\hline Thermal Expansion & $112-125 \times 10^{-6} \mathrm{~K}^{-1}$ \\
\hline Thermal diffusivity & $0,124 \mathrm{~mm}^{2} / \mathrm{s}$ \\
\hline Young's Modulus & $0,5 \mathrm{GPa}$ \\
\hline Yield Strength & $23 \mathrm{MPa}$ \\
\hline Bulk Resistivity & $10^{16} \Omega-\mathrm{m}$ \\
\hline Coefficient of Friction & $0,05-0,10$ \\
\hline Dielectric Constant & $\varepsilon=2,1 \tan (\delta)<5(-4)$ \\
\hline Dielectric Constant $(60 \mathrm{~Hz})$ & $\varepsilon=2,1 \tan (\delta)<2(-4)$ \\
\hline Dielectric Strength (1 MHz) & $60 \mathrm{MV} / \mathrm{m}$ \\
\hline \multicolumn{2}{|c|}{ Tembaga } \\
\hline Property & Value \\
\hline Phase & Solid \\
\hline Melting Point & $1357,77 \mathrm{~K}\left(1084,62^{\circ} \mathrm{C} ; 1984,32^{\circ} \mathrm{F}\right)$ \\
\hline Boiling Point & $2835 \mathrm{~K}\left(2562^{\circ} \mathrm{C} ; 4643^{\circ} \mathrm{F}\right)$ \\
\hline Density near r.t. & $8,96 \mathrm{~g} / \mathrm{cm}^{3}$ \\
\hline when liquid, at m.p. & $8,02 \mathrm{~g} / \mathrm{cm}^{3}$ \\
\hline Heat of Fusion & $13,26 \mathrm{~kJ} / \mathrm{mol}$ \\
\hline Heat of Vaporization & $300,4 \mathrm{~kJ} / \mathrm{mol}$ \\
\hline Molar Heat Capacity & $24440 \mathrm{~J} /(\mathrm{mol}-\mathrm{K})$ \\
\hline Thermal Expansion & $16,5 \mu \mathrm{m} /(\mathrm{m}-\mathrm{K})\left(\right.$ at $\left.25^{\circ} \mathrm{C}\right)$ \\
\hline Thermal Conductivity & $401 \mathrm{~W} /(\mathrm{m}-\mathrm{K})$ \\
\hline Electrical Resistivity & $16,78 \mathrm{n} \Omega-\mathrm{m}\left(\right.$ at $\left.20^{\circ} \mathrm{C}\right)$ \\
\hline Magnetic Ordering & Diamagnetic \\
\hline Young's Modulus & 110- $128 \mathrm{Gpa}$ \\
\hline Shear Modulus & $48 \mathrm{GPa}$ \\
\hline Bulk Modulus & $140 \mathrm{GPa}$ \\
\hline Poisson Ratio & 0,34 \\
\hline Mohs Hardness & 3,0 \\
\hline Vickers Hardness & $343-369 \mathrm{MPa}$ \\
\hline Brinell Hardness & $235-878 \mathrm{MPa}$ \\
\hline CAS Number & $7440-50-8$ \\
\hline
\end{tabular}

Berikut adalah langkah-langkah yang akan dilakukan untuk menganalisa dan juga melakukan perhitungan gaya pada roller. Mendapatkan data-data parameter yang dibutuhkan untuk melakukan analisa, seperti berat, dimensi, material, radius, torsi dan kecepatan.

Memvariasikan kecepatan dari driver pulley, yaitu $1700 \mathrm{rpm}$, $3400 \mathrm{rpm}, 5100 \mathrm{rpm}, 6800 \mathrm{rpm}$ dan $8500 \mathrm{rpm}$. Menggambar diagram benda bebas dari kedua jenis roller (Free Body Diagram). Mengukur radius gerak roller menjadi 5 titik yang telah ditentukan, yaitu Titik $1=29,342 \mathrm{~mm}$; Titik $2=31,397$ $\mathrm{mm}$; Titik $3=33,126 \mathrm{~mm}$; Titik $4=34,443 \mathrm{~mm}$; Titik $5=$ $35,007 \mathrm{~mm}$, seperti pada gambar 9 .

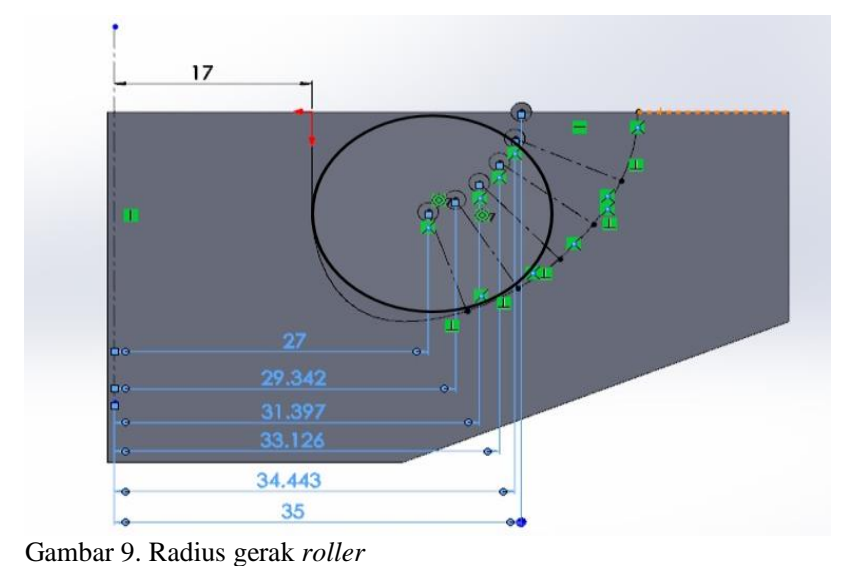

Menghitung gaya sentrifugal pada roller dengan rumusan $F_{C}=$ $\frac{m \cdot v^{2}}{r}$ menjadi $F_{c}=m \omega^{2} r$, Mencari $\theta_{1}, \theta_{2}, \theta_{b 1}$ dan $\theta_{b 2}$ untuk menghitung gaya normal roller terhadap pulley, gaya normal belt terhadap pulley dan gaya tegang belt dengan menggunakan metode grafis, Menganalisa, menguraikan dan menghitung gaya normal roller terhadap pulley, gaya normal pulley penggerak terhadap belt, gaya tegang belt, total gaya yang diterima oleh roller baik itu dari belt, pulley maupun dari roller itu sendiri, besar tegangan total yang terjadi pada round roller dan sliding roller. Memprediksi umur round roller dan sliding roller menggunakan teori kelelahan (fatigue). Kesimpulan yang didapatkan.

\section{HASIL DAN DISKUSI}

Data Kendaraan - Pada penelitian ini diperlukan beberapa data untuk pengolahan analisa baik teoritis simulasi maupun eksperimen yang dapat diperoleh dari perhitungan manual ataupun dari sumber yang lain. Untuk mempermudah menganalisa gaya dan tegangan yang dialami roller akan dibagi menjadi 5 titik statis dari lintasan roller seperti pada tabel 2.

Tabel 2 .

Data spesifikasi roller pada 5 titik statis

\begin{tabular}{cccccc}
\hline \multicolumn{6}{c}{ Data spesifikasi roller pada 5 titik statis } \\
Posisi & $\begin{array}{c}\boldsymbol{M} \\
(\mathbf{k g})\end{array}$ & $\begin{array}{c}\boldsymbol{n} \\
(\mathbf{r p m})\end{array}$ & $\begin{array}{c}\boldsymbol{\omega} \\
(\mathbf{r a d} / \mathbf{s})\end{array}$ & $\begin{array}{c}\boldsymbol{R} \\
(\mathbf{m m})\end{array}$ & $\boldsymbol{R}(\mathbf{m})$ \\
\hline 1 & 0,018 & 1700 & 177,933 & 29,342 & 0,0293 \\
2 & 0,018 & 3400 & 355,867 & 31,397 & 0,0314 \\
3 & 0,018 & 5100 & 533,800 & 33,126 & 0,0331 \\
4 & 0,018 & 6800 & 711,733 & 34,443 & 0,0344 \\
5 & 0,018 & 8500 & 889,667 & 35,000 & 0,0350 \\
\hline \hline
\end{tabular}

Sudut-sudut yang dibutuhkan pada proses analisa yaitu $\theta_{1}$ adalah sudut normal dari gaya sentrifugal terhadap pulley, $\theta_{2}$ adalah sudut normal dari gaya sentrifugal terhadap ramp plate, $\theta_{b 1}$ adalah sudut antara normal roller pulley dan normal pulley belt, dan $\theta_{b 2}$ adalah sudut normal belt terhadap pulley. Pencarian sudut-sudut tersebut menggunakan metode grafis, yaitu dengan cara memvektorkan arah gaya yang sudah diketahui pada roller seperti yang ditunjukkan pada tabel 3 . 
Tabel 3.

\begin{tabular}{ccccc}
\multicolumn{5}{c}{ Hasil pencarian sudut $\theta_{1}, \theta_{2}, \theta_{b 1}$ dan $\theta_{b 2}$} \\
\hline \hline Posisi & $\begin{array}{c}\boldsymbol{\theta}_{\boldsymbol{1}} \\
(\mathbf{d e g})\end{array}$ & $\begin{array}{c}\boldsymbol{\theta}_{\mathbf{2}} \\
(\mathbf{d e g})\end{array}$ & $\begin{array}{c}\boldsymbol{\theta}_{\boldsymbol{b} 1} \\
(\mathbf{d e g})\end{array}$ & $\begin{array}{c}\boldsymbol{\theta}_{\boldsymbol{b} \mathbf{2}} \\
(\mathbf{d e g})\end{array}$ \\
\hline 1 & 57,329 & 69,687 & 16,507 & 73,836 \\
2 & 46,510 & 69,687 & 27,325 & 73,836 \\
3 & 36,153 & 69,687 & 37,682 & 73,836 \\
4 & 23,677 & 69,687 & 50,158 & 73,836 \\
5 & 4,279 & 69,687 & 69,556 & 73,836 \\
\hline \hline
\end{tabular}

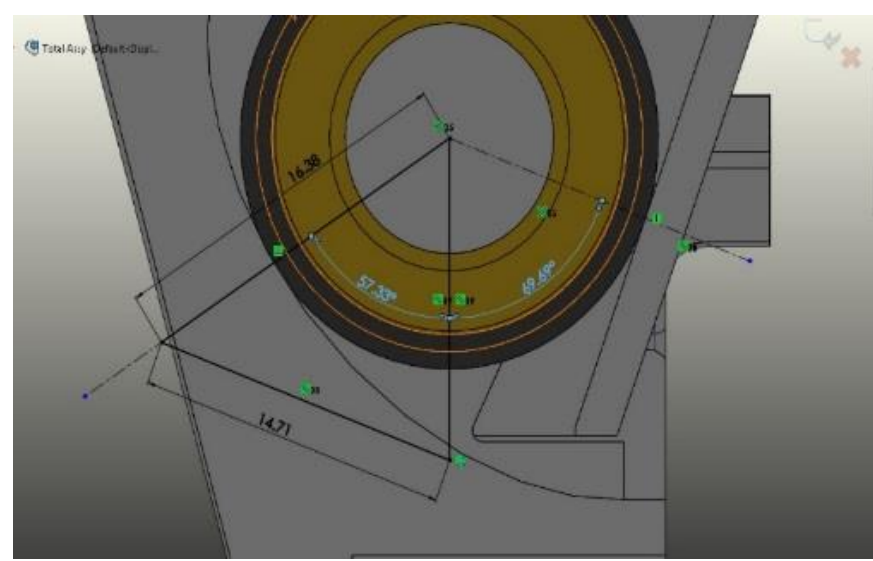

Gambar 10. Ilustrasi Metode Grafis mencari $\theta_{1}$ dan $\theta_{2}$

Perhitungan yang dilakukan yaitu secara teoritis untuk mencari gaya sentrifugal $\left(F_{c}\right)$, gaya normal roller terhadap pulley $\left(R_{I}\right)$, gaya normal roller terhadap ramp plate $\left(R_{2}\right)$, gaya gesek roller pada titik kontak $1\left(F_{s I}\right)$, gaya gesek roller pada titik kontak $1\left(F_{s I}\right)$, gaya normal pulley terhadap belt $\left(R_{b}\right)$, dan gaya tegang belt $\left(F_{b}\right)$. Perhitungan Gaya Sentrifugal $\left(F_{c}\right)$ di titik 1 dengan rumusan:

$F_{c}=m \omega^{2} r$

Perhitungan gaya gesek pada di titik 1 dengan koefisien gesek statis $\left(\mu_{s}\right)$ PTFE dengan Aluminium adalah sebesar 0,19 maka didapat besar gaya gesek yang terjadi pada roller di titik kontak 1 adalah

$\mathrm{Fs}=\frac{\mathrm{N}}{\mu_{\mathrm{s}}}$

Perhitungan gaya normal roller terhadap pulley $\left(R_{l}\right)$ di titik 1 , diagram benda bebas dapat dilihat pada gambar 11 .

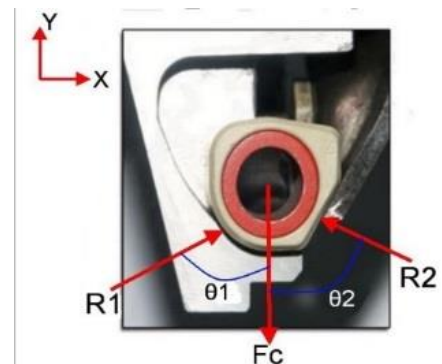

Gambar 11. FBD Gaya Normal Roller Terhadap Pulley $\left(R_{1}\right.$ dan Ramp plate $\left.\left(R_{2}\right)\right)$

$\sum F=m \cdot a=0$

$F_{c}-R_{1 y}-R_{2 y}=0$

$$
\begin{aligned}
& F_{c}-R_{1} \cos \theta_{1}-R_{2} \cos \theta_{2}=0 \\
& R_{1} \cos \theta_{1}-R_{2} \cos \theta_{2}=F_{c} \\
& \sum F_{x}=m \cdot a=0 \\
& R_{1 x}-R_{2 x}=0 \\
& R_{1} \sin \theta_{1}-R_{2} \sin \theta_{2}=0 \\
& R_{1}=\frac{R_{2} \sin \theta_{2}}{\sin \theta_{1}}
\end{aligned}
$$

Perhitungan Gaya Normal Roller Terhadap Ramp plate $\left(R_{2}\right)$ di titik 1 Dari Perumusan perhitungan gaya normal roller terhadap pulley $\left(R_{l}\right)$, maka didapatkan rumusan untuk perhitungan gaya normal roller terhadap ramp plate $\left(R_{2}\right)$ sebagai berikut, hasil

\begin{tabular}{|c|c|c|c|c|}
\hline$F_{c}(\mathrm{~N})$ & $R_{I}(\mathrm{~N})$ & $R_{2}(\mathrm{~N})$ & $F_{s l}(\mathrm{~N})$ & $F_{s 2}(\mathrm{~N})$ \\
\hline 16,722 & 19,640 & 17,629 & 3,732 & 3,349 \\
\hline 71,571 & 74,803 & 57,868 & 14,213 & 10,995 \\
\hline 169,902 & 165,625 & 104,189 & 31,469 & 19,796 \\
\hline 314,057 & 295,034 & 126,337 & 56,056 & 24,004 \\
\hline 498,649 & 486,567 & 38,712 & 92,448 & 7,355 \\
\hline
\end{tabular}
perhitungan dapat dilihat pada tabel 4 .

$R_{2}=\frac{F_{c} \sin \theta_{1}}{\sin \theta_{1}+\left(\cos \theta_{2} \cdot \sin \theta_{1}\right)}$

Tabel 4

Hasil perhitungan teoritis

Tegangan normal pada roller terjadi pada sliding roller titik kontak kedua, yaitu titik kontak antara sliding roller dan ramp plate. Rumusan Tegangan Normal $\sigma=\frac{F}{A} \quad$ dimana luasan kontak untuk sliding roller pada titik kontak kedua $\left(A_{2}\right.$-SR) adalah $143 \mathrm{~mm}^{2}=0,000143 \mathrm{~m}^{2}$, dengan gaya reaksi posisi 1 pada titik kontak kedua sebesar 17,629 N. Hasil perhitungan dapat dilihat pada tabel 5 .

Tabel 5

Hasil perhitungan tegangan normal sliding roller pada titik kontak kedua

\begin{tabular}{ccc}
\hline \hline Posisi & $\boldsymbol{A}_{\mathbf{3}}$-SR $\left.\mathbf{( m}^{\mathbf{2}}\right)$ & $\boldsymbol{\sigma}_{3}$-SR $(\mathbf{M P a})$ \\
\hline 1 & 0,000143 & $\mathbf{0 , 1 2 3}$ \\
2 & 0,000143 & $\mathbf{0 , 4 0 5}$ \\
3 & 0,000143 & $\mathbf{0 , 7 2 9}$ \\
4 & 0,000143 & $\mathbf{0 , 8 8 3}$ \\
5 & 0,000143 & $\mathbf{0 , 2 7 1}$ \\
\hline \hline
\end{tabular}

Perhitungan tegangan kontak (contact stress) pada round roller dan sliding roller di titik 1 kontak 1 dari persamaan (2). Hasil perhitungan dapat dilihat pada tabel 6, dimana,

$F \quad=$ gaya yang bekerja $(19,64 \mathrm{~N})$

$L \quad=$ panjang kontak silinder / roller $(15 \mathrm{~mm})$

$V_{l}=$ poisson's ratio objek $1 /$ roller $($ Teflon $=0,46)$

$V_{2}=$ poisson's ratio objek $2 /$ variator (Aluminium $=0,35$ )

$E_{1}=$ modulus elastisitas objek $1 /$ roller $($ Teflon $=0,5 \mathrm{GPa})$

$E_{2} \quad=$ modulus elastisitas objek $2 /$ variator

(Aluminium $=70 \mathrm{GPa}$ )

$d_{1}=$ diameter objek $1 /$ roller $(20 \mathrm{~mm})$

$d_{2}=$ diameter objek $2 /$ variator $( \pm 40 \mathrm{~mm})$ 
Tabel 6.

\begin{tabular}{cccc}
\multicolumn{4}{c}{ Hasil perhitungan lebar bidang kontak pada titik kontak 1 dan 2 } \\
\hline $\boldsymbol{b}_{\boldsymbol{1}} \mathbf{( \mathbf { m m } )}$ & $\boldsymbol{b}_{\boldsymbol{2}} \mathbf{( \mathbf { m m } )}$ & $\boldsymbol{A}_{\boldsymbol{b} \boldsymbol{1}}\left(\mathbf{m}^{\mathbf{2}}\right)$ & $\boldsymbol{A}_{\boldsymbol{b} \mathbf{2}} \mathbf{( \mathbf { m m } ^ { \mathbf { 2 } } )}$ \\
\hline $\mathbf{0 , 2 3 0}$ & 0,154 & 0,007 & 0,005 \\
$\mathbf{0 , 4 4 9}$ & 0,279 & 0,013 & 0,008 \\
$\mathbf{0 , 6 6 8}$ & 0,375 & 0,020 & 0,011 \\
$\mathbf{0 , 8 9 2}$ & 0,413 & 0,027 & 0,012 \\
$\mathbf{1 , 1 4 6}$ & 0,228 & 0,034 & 0,007 \\
\hline \hline
\end{tabular}

Perhitungan tekanan maksimal (Maximum Pressure) yang dialami roller $\left(P_{\max }\right)$ dengan rumusan dari persamaan (3), Hasil perhitungan dapat dilihat pada tabel 7.

Tabel 7.

Hasil perhitungan tekanan maksimal roller pada titik kontak 1 dan 2

\begin{tabular}{ccc}
\hline \hline Posisi & $\begin{array}{c}\boldsymbol{P}_{\max 1} \\
(\mathbf{M P a})\end{array}$ & $\begin{array}{c}\boldsymbol{P}_{\max 2} \\
(\mathbf{M P a})\end{array}$ \\
\hline 1 & 3,620 & 4,851 \\
2 & 7,065 & 8,788 \\
3 & 10,513 & 11,792 \\
4 & 14,032 & 12,985 \\
5 & 18,019 & 7,188 \\
\hline \hline
\end{tabular}

Perhitungan tegangan utama Roller (Principal Stress) arah X, $\mathrm{Y}$ dan $\mathrm{Z}$ dengan rumusan dari persamaan (4), (5) dan (6), Hasil perhitungan dapat dilihat pada tabel 8 .

Tabel 8.

Hasil perhitungan tegangan utama roller (principal stress) arah $x, y$ dan $z$ pada titik kontak 1 dan 2

\begin{tabular}{cccc}
\hline \hline Posisi & $\begin{array}{c}\sigma_{x} \text { Total } \\
(\mathbf{M P a})\end{array}$ & $\begin{array}{c}\boldsymbol{\sigma}_{\boldsymbol{y}} \text { Total } \\
(\mathbf{M P a})\end{array}$ & $\begin{array}{c}\boldsymbol{\sigma}_{z} \text { Total } \\
(\mathbf{M P a})\end{array}$ \\
\hline 1 & $-3,713$ & $-1,494$ & $-6,578$ \\
2 & $-7,083$ & $-2,938$ & $-12,459$ \\
3 & $-9,964$ & $-4,132$ & $-17,528$ \\
4 & $-12,072$ & $-5,009$ & $-21,235$ \\
5 & $-11,261$ & $-4,671$ & $-19,810$ \\
\hline \hline
\end{tabular}

Perhitungan tegangan geser (shear stress) bidang $x$ arah $z\left(\tau_{x z}\right)$, bidang $y$ arah $z\left(\tau_{y z}\right)$ dan bidang $x$ arah $y\left(\tau_{x y}\right)$, Hasil perhitungan dapat dilihat pada tabel 9 , dengan rumusan,

$\tau_{x z}=\frac{\sigma_{x}-\sigma_{z}}{2}$

$\tau_{y z}=\frac{\sigma_{y}-\sigma_{z}}{2}$

$\tau_{\mathrm{xy}}=\frac{\mathrm{F}_{\mathrm{s}}}{\mathrm{A}_{\mathrm{b} 1}}$

Tabel 9.

\begin{tabular}{ccccc}
\multicolumn{4}{c}{ Hasil perhitungan tegangan geser roller (shear stress) } \\
\hline \hline Posisi & $\begin{array}{c}\boldsymbol{\tau}_{\boldsymbol{x} z} \text { Total } \\
(\mathbf{M P a})\end{array}$ & $\begin{array}{c}\boldsymbol{\tau}_{\boldsymbol{y z}} \text { Total } \\
(\mathbf{M P a})\end{array}$ & $\begin{array}{c}\boldsymbol{\tau}_{\boldsymbol{x}} \\
\text { Round } \\
(\mathbf{M P a})\end{array}$ & $\begin{array}{c}\boldsymbol{\tau}_{\boldsymbol{x}} \\
\text { Sliding } \\
(\mathbf{M P a})\end{array}$ \\
\hline 1 & 1,432 & 2,542 & 0,00126 & 0,02396 \\
2 & 2,688 & 4,761 & 0,00237 & 0,07794 \\
3 & 3,782 & 6,698 & 0,00333 & 0,14000 \\
4 & 4,581 & 8,113 & 0,00403 & 0,16995 \\
5 & 4,274 & 7,569 & 0,00376 & 0,05413 \\
\hline \hline
\end{tabular}

Dan yang terakhir menghitung tegangan ekivalen (equivalent stress) menggunakan perumusan Von Mises, Hasil perhitungan dapat dilihat pada tabel 10 dan pada gambar 12 .

$$
\sigma^{\prime}=\frac{1}{\sqrt{2}}\left[\begin{array}{c}
\left.\left(\sigma_{x}-\sigma_{y}\right)^{2}+\left(\sigma_{y}-\sigma_{z}\right)^{2}+\left(\sigma_{z}-\sigma_{x}\right)^{2}+\right]^{\frac{1}{2}} \\
6\left(\tau_{x y}{ }^{2}+\tau_{y z}{ }^{2}+\tau_{z x}{ }^{2}\right)
\end{array}\right]^{2}
$$

Tabel 10.

Hasil perhitungan tegangan ekivalen roller (equivalent stress) pada titik kontak 1 dan 2

\begin{tabular}{cccc}
\hline \hline $\boldsymbol{\sigma}^{\prime} \mathbf{1}(\mathbf{M P a})$ & $\boldsymbol{\sigma}^{\prime} \mathbf{2}(\mathbf{M P a})$ & $\begin{array}{c}\boldsymbol{\sigma}^{\prime} \text { Total } \\
\text { Round }(\mathbf{M P a})\end{array}$ & $\begin{array}{c}\boldsymbol{\sigma}^{\prime} \text { Total } \\
\text { Sliding }(\mathbf{M P a})\end{array}$ \\
\hline $\mathbf{2 , 8 7 0 7 2}$ & 3,83922 & 6,70994 & 3,01796 \\
$\mathbf{5 , 6 0 2 5 7}$ & 6,96869 & 12,57126 & 6,08519 \\
$\mathbf{8 , 3 3 6 4 8}$ & 9,35073 & 17,68720 & 9,20507 \\
$\mathbf{1 1 , 1 2 6 6 1}$ & 10,29667 & 21,42328 & 12,18004 \\
$\mathbf{1 4 , 2 8 8 7 4}$ & 5,69968 & 19,98843 & 14,61358 \\
\hline \hline
\end{tabular}

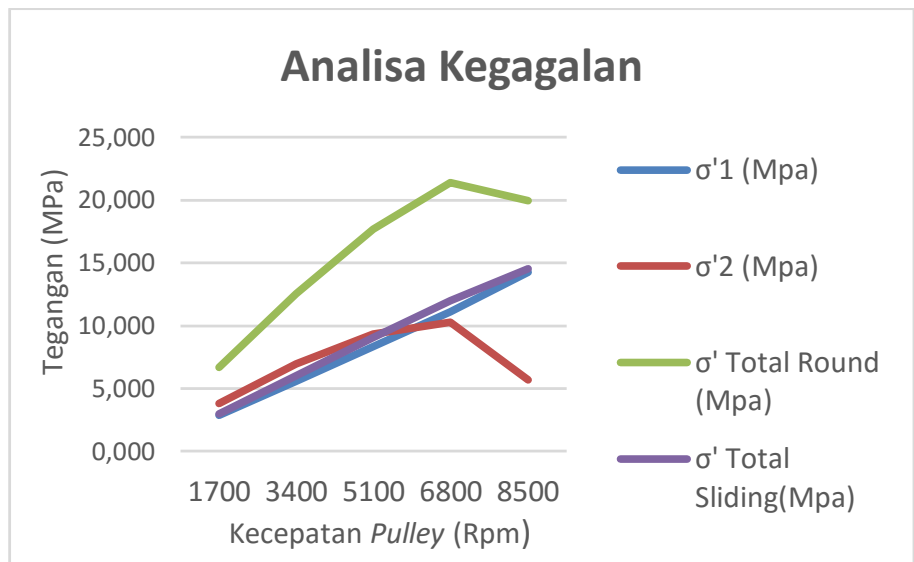

Gambar 12. Grafik analisa kegagalan Von Mises

Perhitungan teori kelelahan (fatigue) pada round roller dan sliding roller untuk memprediksi umur roller, untuk memprediksi umur dari roller akan digunakan teori kelelahan (fatigue) dikenakan tegangan yang berulang-ulang maka akan terjadi kegagalan. Akan digunakan teori kelelahan gerber dikarenakan pada umumnya, data pengujian untuk material lentur (ductile) mendekati parabola Gerber seperti pada gambar 7 perumusan nya adalah sebagai berikut.

Dimana:

$$
\frac{1}{F . S .}=\left[\frac{\sigma_{m}}{\sigma_{u}}\right]^{2} \times F . S+\frac{\sigma_{v}}{\sigma_{e}}
$$

F.S. : Faktor Keamanan [1]

$\sigma_{m}:$ Tegangan Rata-rata $=\frac{\sigma_{\max }+\sigma_{\min }}{2}=\frac{21,423+6,710}{2}$

$$
=14,071 \mathrm{MPa}
$$

$\sigma_{u} \quad$ : Tegangan Ultimate $(\mathrm{PTFE}=34 \mathrm{MPa})$

$\sigma_{v}$ : Tegangan Variabel / Amplitudo tegangan

$$
=\frac{\sigma_{\max }-\sigma_{\min }}{2}=\frac{21,423-6.710}{2}=7,357 \mathbf{M P a}
$$

$\sigma_{e} \quad$ : Batas ketahanan untuk beban berlawanan (reversal stress)

Jadi,

$\frac{1}{1}=\left[\frac{14,071}{23}\right]^{2} \times 1+\frac{7,357}{\sigma_{e}} ; 1=\frac{7,357}{\sigma_{e}}+0,17116$

$0,82884=\frac{7,357}{\sigma_{e}} \sigma_{\mathrm{e}}=\mathbf{8 , 8 7 5 6} \mathbf{M P a}$ 
Untuk sliding roller dengan perumusan yang sama akan tetapi untuk tegangan rata-rata $\left(\sigma_{m}\right)$, tegangan variabel / amplitudo tegangan $\left(\sigma_{v}\right)$ dan batas ketahanan (endurance limit) $\left(\sigma_{e}\right)$ berbeda dengan round roller:

$$
\frac{1}{F . S .}=\left[\frac{\sigma_{m}}{\sigma_{u}}\right]^{2} \times F . S+\frac{\sigma_{v}}{\sigma_{e}}
$$

Dimana:

F.S. : Faktor Keamanan [1]

$$
\sigma_{m}: \text { Tegangan Rata-rata }=\frac{\sigma_{\max }+\sigma_{\min }}{2}=\frac{14,559+2,994}{2}
$$

$\sigma_{u} \quad:$ Tegangan Ultimate $(\mathrm{PTFE}=34 \mathrm{MPa})$

$\sigma_{v} \quad$ : Tegangan Variabel /Amplitudo tegangan

$=\frac{\sigma_{\max }-\sigma_{\min }}{2}=\frac{14,559-2.994}{2}=\mathbf{5 , 7 8 2} \mathrm{MPa}$

$\sigma_{e} \quad$ : Batas ketahanan untuk beban berlawanan (reversal stress)

Jadi,

$\frac{1}{1}=\frac{8,776}{23} \times 1+\frac{5,782}{\sigma_{e}} ; 1=\frac{5,782}{\sigma_{e}}+0,0666$

$0,9334=\frac{5,7825}{\sigma_{e}} ; \sigma_{\mathrm{e}}=\mathbf{6 , 1 9 5} \mathbf{M P a}$

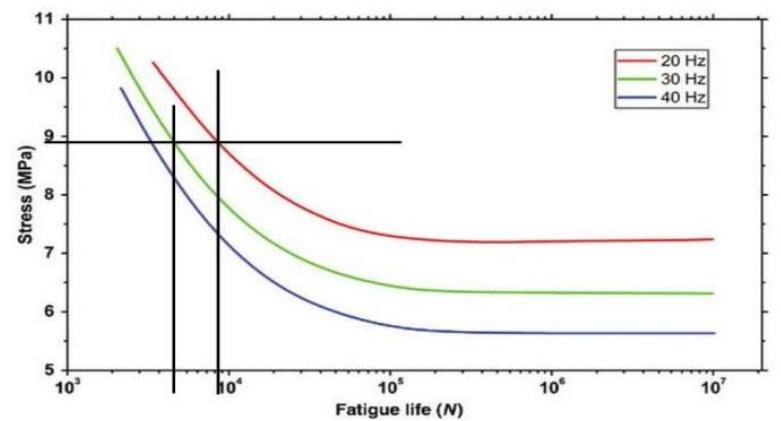

Gambar 13. Kurva amplitudo tegangan (stress amplitude) vs siklus (cycle) sncurve material PTFE round roller [4]

Untuk frekuensi pembebanan real didapat dari mengkorelasikan waktu yang dibutuhkan motor dari kecepatan 0 menuju kecepatan maksimum yaitu selama \pm 10 detik, dan dari kecepatan maksimum menuju 0 yaitu selama \pm 5 detik, maka 1 periode siklus roller didapat \pm 15 detik. Jadi dengan perumusan frekuensi $f=1 / T$, didapatkan nilai frekuensi pembebanan real roller sebesar 0,0667 Hz.

Untuk round roller, amplitudo tegangan (Stress Amplitude) didapatkan nilai sebesar $8,8756 \mathrm{MPa}$, sehingga akan didapatkan berapa siklus akan dilalui yaitu kurang lebih sebanyak $85 \times 10^{3}$ siklus untuk kurva merah $(20 \mathrm{~Hz})$ dan $45 \times 10^{3}$ siklus untuk kurva hijau $(30 \mathrm{~Hz})$. Dan untuk frekuensi pembebanan real dari roller yaitu $0,0667 \mathrm{~Hz}$ akan dilakukan ekstrapolasi, dan didapatkan hasilnya adalah $65 \times 10^{4}$ siklus.

Jika waktu yang dibutuhkan untuk 1 periode siklus adalah \pm 15 detik, dan didapat sebesar $65 \times 10^{4}$ siklus dikalikan 15 detik jadi prediksi umur pakai round roller adalah 2708,33 jam atau 112,847 hari atau 16,121 minggu atau $4,03 \approx 4$ Bulan. Dari buku pedoman reparasi honda vario 125 PGM-Fi menyatakan bahwa penggantian roller dan belt adalah setiap $8000 \mathrm{Km}$, jika jarak Surabaya-Sidoarjo adalah $35 \mathrm{Km}$, maka bisa dipakai untuk 114,256 $\approx 114$ kali Pulang Pergi. Dan jika dalam 1 hari motor dipakai 1 kali PP, maka umur pakai roller adalah 114,256 $\approx 114$ hari atau $16,322 \approx 16$ minggu atau $4,081 \approx 4$ Bulan.

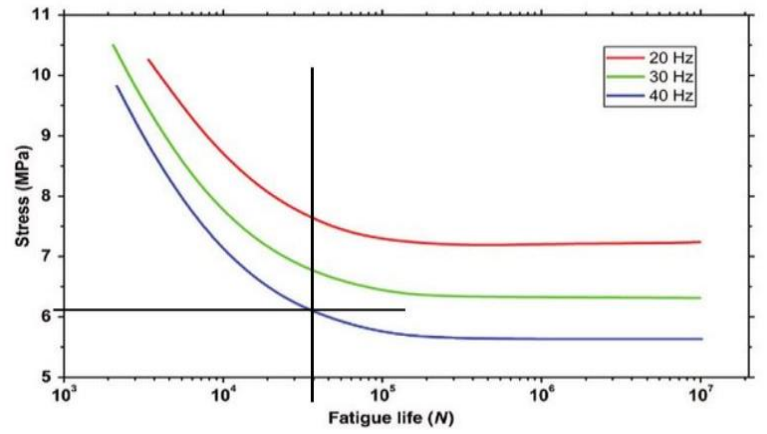

Gambar 14. Kurva amplitudo tegangan (stress amplitude) vs siklus (cycle) sncurve material PTFE sliding roller [5]

Sedangkan untuk sliding roller, amplitudo tegangan (Stress Amplitude) didapatkan nilai sebesar 6,195 MPa, setelah itu ditarik garis lurus horizontal sehingga akan memotong kurva warna biru, pada perpotongan garis ditarik garis lurus vertical sehingga akan didapatkan berapa siklus akan dilalui yaitu kurang lebih sebanyak $35 \times 10^{4}$ siklus untuk kurva merah (40 $\mathrm{Hz}$ ) dan dilinierkan dengan $75 \times 10^{3}$ siklus. Dan untuk frekuensi pembebanan real dari roller yaitu $0,0667 \mathrm{~Hz}$ akan dilakukan ekstrapolasi, dan didapatkan hasilnya adalah $95 \times 10^{4}$ siklus.

Jika waktu yang dibutuhkan untuk 1 periode siklus adalah \pm 15 detik, dan didapat sebesar $95 \times 10^{4}$ siklus dikalikan 15 detik jadi prediksi umur pakai round roller adalah 3958,333 jam atau 164,93 hari atau 23,561 minggu atau 5,89 $\approx 6$ Bulan. Dari buku pedoman reparasi honda vario 125 PGM-Fi menyatakan bahwa penggantian roller dan belt adalah setiap $8000 \mathrm{Km}$, jika umur pakai yang dihasilkan adalah $\pm \mathbf{6}$ bulan Sliding Roller dapat bertahan selama $12600 \mathrm{Km}$.

\section{KESIMPULAN}

Setelah dilakukan analisa pada round roller dan sliding roller, Total Gaya Normal yang didapatkan untuk round roller dan sliding roller hasilnya adalah sama yaitu pada posisi stasioner sebesar 37,268 $\mathrm{N}$ dan posisi puncak sebesar 525,279 $\mathrm{N}$ akan tetapi untuk total tegangan ekivalen yang terjadi berbeda dikarenakan luasan kontak yang berbeda. Round roller dengan luasan kontak yang lebih kecil menghasilkan total tegangan yang lebih besar yaitu 21,423 MPa sedangkan sliding roller sebesar 14,559 $\mathrm{MPa}$.

Frekuensi pembebanan real roller didapatkan $0,0667 \mathrm{~Hz}$ dan berdasarkan amplitude tegangan yang sudah didaatkan dan diplotkan pada sn-curve didapatkan siklus untuk round roller adalah sebanyak $65 \times 104$ siklus, sedangkan untuk sliding roller adalah sebanyak $95 \times 104$ siklus

Prediksi umur round roller adalah $\pm \mathbf{8 0 0 0} \mathbf{~ K m}$ dan Untuk Sliding roller adalah $\pm \mathbf{1 2 6 0 0} \mathbf{K m}$, dan jika dikorelasikan dengan buku pedoman reparasi honda vario 125 PGM-Fi yang menyatakan bahwa penggantian roller dan belt adalah setiap $8000 \mathrm{Km}$, dengan memakai sliding roller bisa mencapai 12600 $\mathrm{Km}$. 


\section{DAFTAR PUSTAKA}

[1] Sutantra, I. N., \& Sampurno. (2010). Teknologi Otomotif Edisi Kedua. Surabaya: Intitut Teknologi Sepuluh Nopember.

[2] Khurmi, R.S. Gupta, J.K. (2005), a Textbook of Machine Design. New Delhi: Eurasia Publishing House (PVT.) LTD.

[3] Budynas, Richard G. \& Nisbett., J. Keith (2011), Shigley's Mechanical Engineering Design Ninth Edition. New York: McGraw-Hill.

[4] McKeen, Laurence W. (2016) Fatigue and Tribological Properties of Plastics and Elastomers Third Edition. Oxford OX5 IGB UK: Elsevier.

[5] Wijanarko, (2007). Analisa Pengaruh Perubahan Massa Roller Penggerak Variator Pulley Pada Continuously Variable Transmission (CVT) Terhadap Kinerja Traksi Pada Sepeda Motor Yamaha Mio. Surabaya: Institut Teknologi Sepuluh Nopember.

[6] Buku Pedoman Reparasi Honda Vario 125 (2013). PT.Astra Honda Motor. 